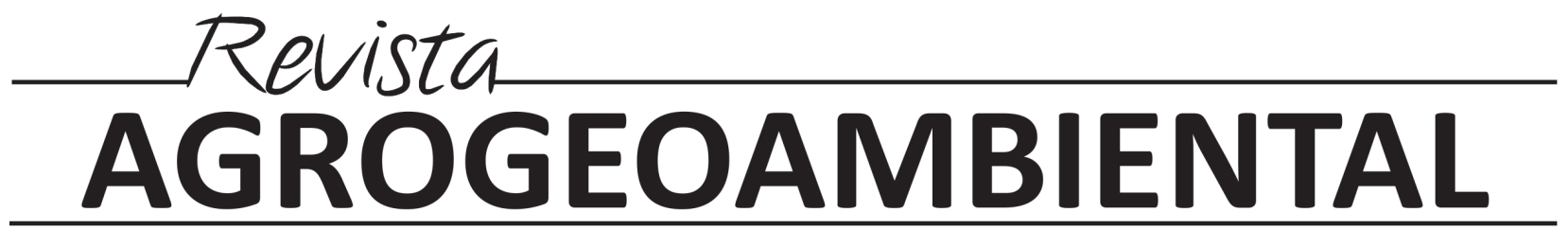

ISSN 1984-428X - eISSN 2316-1817 - Indexação: Sumários.org - E-revist@s - Latindex - DOAJ

\title{
Expediente
}

Editor chefe

José Luiz de Andrade Rezende Pereira

Assistentes editoriais

Kélica Andréa Campos de Souza

Alan Silva Fialho

Comissão editorial

Cristiane Fortes Gris

Jane Piton Serra Sanches

Wellington Marota Barbosa
Estagiária

Thamíris Santos do Nascimento

Secretária

Cássia Mara Ribeiro de Paiva

Arte da capa

Pamela Hélia de Oliveira

Revisão

Triunfal Gráfica e Editora

\section{Avaliadores desta edição}

Ariana Vieira Silva - IFSULDEMINAS

Carlos Enrique Medeiros Jerônimo - Universidade Potiguar

Cristiane Fortes Gris Baldan - IFSULDEMINAS

Danielle Martins Duarte Costa - IFSULDEMINAS

Diego César Terra de Andrade - IFSULDEMINAS

Edu Max da Silva - IFSULDEMINAS

Everton Vinícius Zambiazzi - UFLA

Felipe Santana Machado - UFLA

Francisco César Gonçalves - IF Sudeste

Igor Souza Pereira - IFMT

Jamil de Morais Pereira - IFSULDEMINAS

João Antônio Granja - UFLA

José Luiz de Andrade Rezende Pereira - IFSULDEMINAS

José Venícius de Souza - IFSULDEMINAS

Lilian Vilela Andrade Pinto - IFSULDEMINAS

Rafael Nogueira Scoriza - UFRRJ

Raphael Maia Aveiro Cessa - IFMT

Tiragem de 1.000 exemplares

http://agrogeoambiental.ifsuldeminas.edu.br/ agrogeoambiental@ifsuldeminas.edu.br 


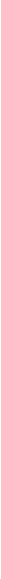




\section{Apresentação}

Em um momento de crise mundial, caracterizado pela carência de recursos de toda ordem, pela escassez de recursos naturais e por desastres no ambiente onde vivemos, a pesquisa aplicada e o gerenciamento eficiente dos recursos naturais serão extremamente importantes para o futuro da humanidade.

Nesta edição, a Revista Agrogeoambiental traz 10 excelentes artigos que contribuirão com ideias inovadoras para a gestão e aproveitamento dos recursos naturais.

A utilização de lodo da estação de tratamento de água, tratamento de resíduos de laticínios, doenças foliares de milho, cooperativismo no agronegócio, desbaste químico da bananeira, doenças da cultura do morango, vespas sociais em lavouras de cafés do Sul de Minas e seleção de cultivares de soja para o Sul de Minas foram os temas abordados pelos autores que publicaram nesta edição.

Desejo a todos uma excelente leitura e bom proveito dos trabalhos.

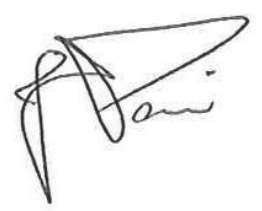

José Luiz de Andrade Rezende Pereira

Editor-chefe 